\title{
ASYNCHRONOUS DEVELOPMENT OF STIGMATIC RECEPTIVITY IN THE PEAR (PYRUS COMMUNIS; ROSACEAE) FLOWER ${ }^{1}$
}

\author{
JaVier SAnzol, ${ }^{2,4}$ Pilar Rallo, ${ }^{3}$ And María Herrero ${ }^{2}$ \\ ${ }^{2}$ Departamento de Fruticultura, SIA-DGA, Campus de Aula-Dei, P.O. Box 727, 50080 Zaragoza, Spain; and \\ ${ }_{3}^{3}$ Instituto de Agricultura Sostenible-CSIC, Alameda del Obispo s/n, P.O. Box 4080, 14080 Córdoba, Spain
}

\begin{abstract}
While stigma anatomy is well documented for a good number of species, little information is available on the acquisition and cessation of stigmatic receptivity. The aim of this work is to characterize the development of stigma receptivity, from anthesis to stigma degeneration, in the pentacarpellar pear (Pyrus communis) flower. Stigma development and stigmatic receptivity were monitored over two consecutive years, as the capacity of the stigmas to offer support for pollen germination and pollen tube growth. In an experiment where hand pollinations were delayed for specified times after anthesis, three different stigmatic developmental stages could be observed: (1) immature stigmas, which allow pollen adhesion but not hydration; (2) receptive stigmas, which allow proper pollen hydration and germination; and (3) degenerated stigmas, in which pollen hydrates and germinates properly, but pollen tube growth is impaired soon after germination. This developmental characterization showed that stigmas in different developmental stages coexist within a flower and that the acquisition and cessation of stigmatic receptivity by each carpel occur in a sequential manner. In this way, while the duration of stigmatic receptivity for each carpel is rather short, the flower has an expanded receptive period. This asynchronous period of receptivity for the different stigmas of a single flower is discussed as a strategy that could serve to maximize pollination resources under unreliable pollination conditions.
\end{abstract}

Key words: pollen germination; Pyrus communis; Rosaceae; stigma; stigmatic receptivity.

The stigma is required to provide an adequate support for pollen hydration, germination and initial pollen tube growth. Because this occurs for a limited period and at a precise time during flower development, stigma receptivity has important implications in reproductive success of individuals, pollination biology of populations, and breeding system of species (Wyatt, 1983; Kalisz et al., 1999; Cowan, Marshall, and MichaelsonYeates, 2000; Heslop-Harrison, 2000). Further, it is involved in the crop yield of pollination-dependent species, such as fruit trees, and hence is of agricultural significance (Gonzalez, Coque, and Herrero, 1995a, b; Sanzol and Herrero, 2001).

Stigma characterization has been widely illustrated both from an anatomical (Konar and Linskens, 1966a; Heslop-Harrison and Shivanna, 1977; Owens and Kimmins, 1981; Uwate and Lin, 1981; Ghosh and Shivanna, 1982) and biochemical (Konar and Linskens, 1966b; Martin, 1969; Labarca, Kroh, and Loewus, 1970) perspective. This has allowed an understanding of stigma morphology and exudate composition. More recently, some of the mechanisms for pollen hydration, germination and directional pollen tube growth, during pollenstigma interaction, both in wet (Goldman, Goldberg, and Mariani, 1994; Wolters-Arts, Lush, and Mariani, 1998) and dry stigmas (Preuss et al., 1993; Hülskamp et al., 1995; Fiebig et al., 2000) are being elucidated. However, in spite of its relevance, little effort has been devoted to study the processes that control the acquisition and cessation of stigma receptivity (Heslop-Harrison, 2000).

In wet stigmas, stigma receptivity implies the production of exudates rich in proteins, free amino acids, lipids, and carbo-

\footnotetext{
${ }^{1}$ Manuscript received 2 May 2002; revision accepted 19 July 2002.

The authors thank I. Hormaza and A. Hedly for critical reading and helpful comments on the manuscript and A. Escota for photographic technical assistance. J. Sanzol was supported by an INIA fellowship and financial support for this work was also provided by INIA (Project grants SC98-049 and RTA 01-103).

${ }^{4}$ E-mail: jsanzol@aragob.es.
}

hydrates, which sets up a proper environment for pollen hydration, germination, and initial pollen tube growth. This environment also provides a favorable growth medium for plant pathogens such as fungi and bacteria (Willingale, Mantle, and Thakur, 1986; Mansvelt and Hattingh, 1987). It has been proposed that plants could avoid exposure to infectious agents by minimizing stigmatic receptivity (Heslop-Harrison, 2000). Indeed, a short stigma life span has been shown to limit flower receptivity and jeopardize fruit set in a number of species (Guerrero-Prieto, Vasilakakis, and Lombard, 1985; Egea and Burgos, 1992; Gonzalez, Coque, and Herrero, 1995b).

In an ecological context, stigmatic receptivity has been interpreted as a secondary sexual character, whose evolution could be explained in terms of sexual selection (Galen, Shykoff, and Plowright, 1986; Murdy and Carter, 1987). Sexual selection operates via male competition or female choice, and a number of reproductive mechanisms appear to favor genetic variability in male gametophytes. Thus, stigmatic strategies to synchronize pollen germination have been described, which increase the chance of arrival of pollen from several donors and hence the genetic diversity of pollen tubes growing in the style (Murdy and Carter, 1987; Hormaza and Herrero, 1994). Thus, the likelihood of male competition and/or female choice is increased. These mechanisms could also operate in increasing the number of parents involved in fertilization within multi-ovulate ovaries and then favoring the likelihood of multiple paternity (Kress, 1981; Uma-Shaanker, Ganeshaiah, and Bawa, 1988; Juncosa and Webster, 1989; Hormaza and Herrero, 1994; Delph and Havens, 1998). In this context, stigmatic receptivity is thought to be a highly regulated process with clear evolutionary implications. In spite of its importance, the information available about the regulation of stigmatic receptivity is scarce.

This situation is even more obscure in more complex flower structures exhibiting polycarpellar gynoecia with two or more 
stigmas. Flowering plants gynoecia show intricate patterns of carpel number and organization whose evolution are believed to have been greatly determined by trends directed to modulate reproduction (Carr and Carr, 1961; Endress, 1982). Polycarpellar flowers are estimated to represent $89 \%$ of the recent angiosperm species (Endress, 1982). The pear flower exhibits a pentacarpellar syncarpous gynoecium. This basic structure of five fused carpels is found in four subclasses in dicots, from which reduction and increasing trends in carpel number seem to have operated during evolution (Decraene and Smets, 1998). In spite of its importance, limited information exists about the adaptive significance of polycarpellarity as well as on how development of the different carpels within a multicarpellar gynoecium is regulated.

The present work reports the characterization of stigma development and stigmatic receptivity in pear flowers over two consecutive years. The duration of stigmatic receptivity was monitored in an experiment using delayed pollination, as the capability of the stigmas to support pollen germination and pollen tube growth. In a parallel experiment, changes in the stigma were sequentially examined. These changes were related to pollen tube behavior. Finally, the intraflower developmental pattern of stigmatic receptivity for the different carpels was investigated.

\section{MATERIALS AND METHODS}

Plant material and pollination procedures-Pear trees (Pyrus communis L. [Rosaceae] cv. Agua de Aranjuez) grafted on quince rootstocks and located in an experimental orchard were used. Compatible pollen from cv. Castell (Sanzol and Herrero, 2002) was collected from flowers at the balloon stage. The anthers were removed and dried at room temperature in a piece of paper. Pollen was sieved $48 \mathrm{~h}$ later with a $0.26 \mathrm{~mm}$ mesh and stored at $4^{\circ} \mathrm{C}$ until used.

Evaluation of the duration of stigmatic receptivity - Two days before anthesis, flowers at the balloon stage were marked in the tree. Flowers were emasculated by removing the petals and anthers with tweezers to avoid insect visits and self-pollination (Free, 1964). Flowers were divided in six batches and each batch was pollinated at anthesis and 2, 4, 6, 8, and $10 \mathrm{~d}$ after anthesis. Twenty-four hours after pollination, 15 flowers per day of pollination were collected and fixed in FAA (formalin : acetic acid : ethanol 70\%) $(1: 1$ : 18) (Johansen, 1940). Following fixation, pistils were washed with distilled water three times, for $1 \mathrm{~h}$ each wash, and left overnight in 5\% sodium sulfite. On the following day, they were autoclaved for $10 \mathrm{~min}$ at $1 \mathrm{~kg} / \mathrm{cm}^{2}$ (Jefferies and Belcher, 1974) and mounted in squash preparations with $0.1 \%$ aniline blue in $0.1 \mathrm{~N} \mathrm{~K}_{3} \mathrm{PO}_{4}$ (Linskens and Esser, 1957). Preparations were viewed under an Ortholux II (Leitz, Wetzlar, Germany) microscope with UV epifluorescence using a BP 355-425 exciter filter and an LP 460 barrier filter. Stigmatic receptivity was evaluated as the capacity of stigmas to support pollen hydration, germination, and initial pollen tube growth in the transmitting tissue of the style.

Histochemical procedures-For histochemical preparations, emasculated and pollinated flowers as described above were used. For this purpose, five flowers for each day of pollination were fixed $24 \mathrm{~h}$ after pollination in 2.5\% (v/v) glutaraldehyde in $30 \mathrm{mmol} / \mathrm{L}$ phosphate buffer (Sabatini, Bench, and Barrnett, 1963) at $\mathrm{pH}$ 6.8, dehydrated in an ethanol series, and embedded in Historesin (Reichert-Jung, Heidelberg, Germany). Sections, $2 \mu \mathrm{m}$ thick, were stained with $0.07 \%$ calcofluor white for cellulose (Hughes and McCully, 1975), $0.01 \%$ auramine in $0.05 \mathrm{M}$ phosphate buffer ( $\mathrm{pH} 7.8$ ) for cutin (Heslop-Harrison, 1977), and acridine orange $(0.01 \%)$ in $0.03 \%$ phosphate buffer (Nicholas, Gates, and Grierson, 1986) for a general overview of cytoplasm and intercellular matrix. For a general histological examination of the tissue, these stains were also used in combination. Thus, slides were stained with
$0.007 \%$ calcofluor white for $4 \mathrm{~min}$, washed with distilled water, stained with acridine orange $(0.01 \%)$ in $0.03 \%$ phosphate buffer for $3 \mathrm{~min}$, washed again with distilled water, and finally stained with $0.01 \%$ auramine in $0.05 \mathrm{~mol} / \mathrm{L}$ phosphate buffer ( $\mathrm{pH} 7.8$ ), and dried. Then, slides were mounted with immersion oil and viewed with an Ortholux II microscope with UV epifluorescence using a BP 355-425 exciter filter and an LP 460 barrier filter. Insoluble carbohydrates were stained with $0.5 \%$ periodic acid-Schiff reagent (PAS) (Feder and O'Brien, 1968) and viewed in bright-field microscopy.

\section{RESULTS}

Stigma morphology — Pear flowers have an ovary made up of five fused carpels with five independent styles, each one leading to one of the ovary locules in an independent way. Each locule contains two ovules. Thus, pollen grains landing on each stigma will fertilize the ovules of its own carpel. The stigma is wet, with a receptive surface covered by unicellular papillae (Fig. 1). The stigmatic surface is already developed at anthesis, showing turgid papillae with a vacuole filling almost all the cellular space and a cuticular layer covering the cell wall (Fig. 2). At this stage secretion is already visible. This secretion flows from the stigmatoid tissue below the receptive papillar surface. This tissue has intercellular spaces rich in secretion that flow up between papillae. The onset of exudate production precedes the loss of papillar turgidity (Fig. 2). Concomitantly or after the papillae lose turgidity (Fig. 3), pollen grain hydration and germination takes place. Then the pollen tube is oriented and enters the stigmatoid tissue through the interpapillar space.

Stigma maturation and degeneration-To evaluate the duration of stigmatic receptivity, stigmas of flowers pollinated at $0,2,4,6,8$ and $10 \mathrm{~d}$ after anthesis were observed. Depending on pollen behavior, three stigmatic stages could be distinguished-immature, mature, and degenerated. Immature stigmas, while able to support adhesion of pollen on their surface, did not provide a proper substrate for pollen hydration (Fig. 4). In receptive stigmas pollen grains hydrate and germinate, and pollen tubes grow into the stigmatoid tissue (Fig. 5). Thus, $24 \mathrm{~h}$ after pollination in receptive stigmas, pollen tubes had already reached the stylar transmitting tissue and grown approximately $15 \%$ of the stylar length. Finally, degenerated stigmas were not able to sustain normal pollen development and pollen tube growth. Pollen hydrated and germinated properly in such stigmas, but pollen tube growth was impaired soon after germination, showing tip growth abnormalities as swollen ends (Fig. 6), and the pollen tubes were not able to reach the transmitting tissue of the style. In older stigmas pollen germination was impaired and finally adhesion was reduced because pollen grain number per stigma was significantly lower in older stigmas.

With the aim of relating changes in stigma tissue with pollen behavior, semithin sections of resin-embedded stigmas in the three developmental stages studied above were observed. In immature stigmas, papillae were turgid (Fig. 7), although some secretion was already visible between papillae and the other cells of the receptive surface while the stigmatoid tissue was free of intercellular substance (Fig. 8). In mature stigmas papillae had a shrunken appearance (Fig. 9). In these stigmas, the stigmatoid cells had entered a secretory phase and the tissue presented an extracellular matrix rich in secretion (Fig. 10) that also flowed to the stigma surface. In degenerated stigmas, papillae have collapsed (Fig. 11), and in the stigmatoid 

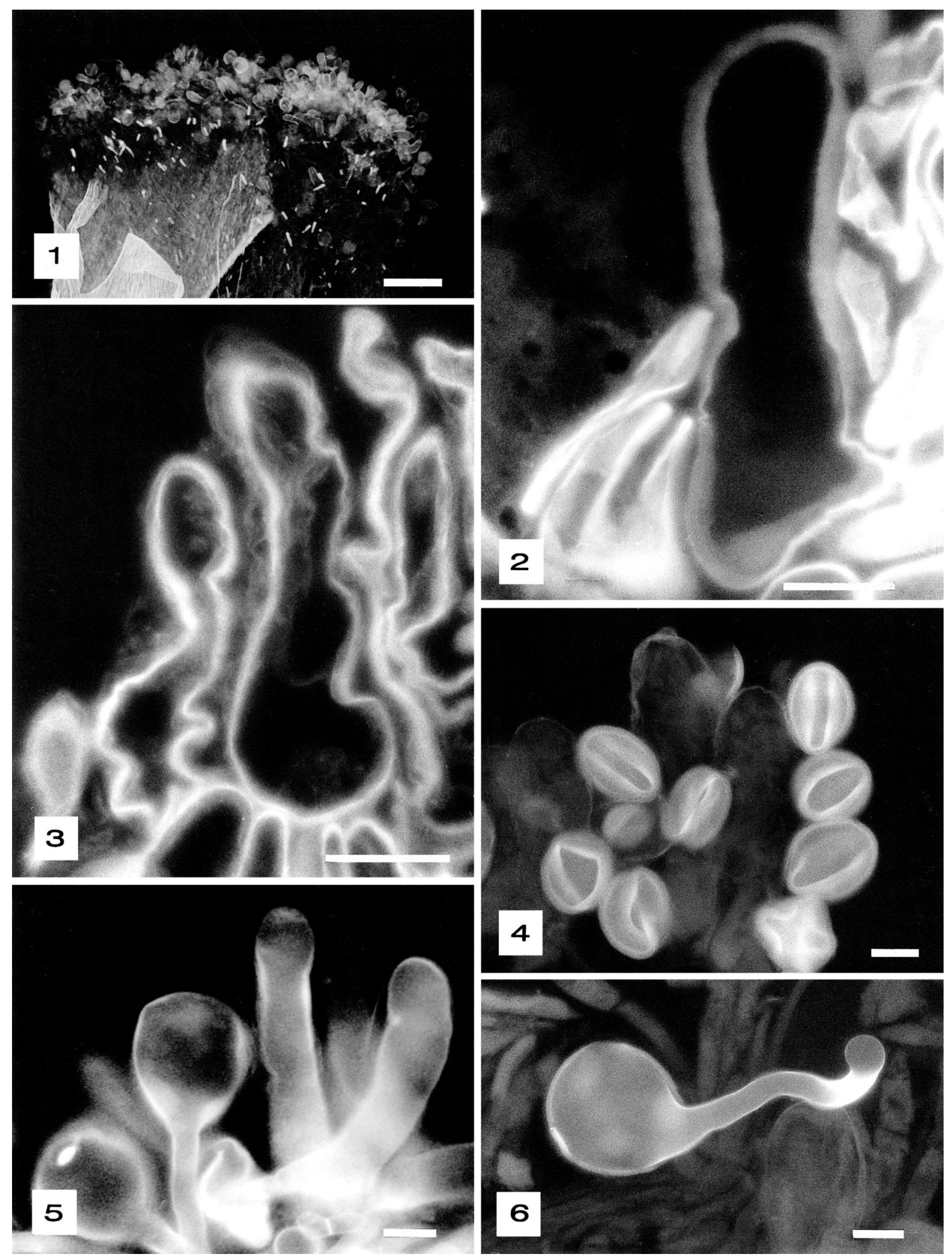

Figs. 1-6. Stigma morphology and pollen-stigma interaction in Pyrus communis. 1. General view of a stigma $24 \mathrm{~h}$ after pollination. Unicellular papillae cover the stigmatic surface. Squash preparation, stained with acridine orange and aniline blue. Bar $=200 \mu \mathrm{m}$. 2. Unicellular papilla of a stigma, $1 \mathrm{~d}$ after anthesis. Papilla is turgid with a vacuole that fills almost all the cellular space. Secretion is already present. Stained with calcofluor white, acridine orange, and auramine. A 2- $\mu \mathrm{m}$ historesin section. 3. Papillae, from a 3-d-old stigma, which have lost turgidity and the cell membrane and cuticle, are detached from the cell wall. Stained with calcofluor white, acridine orange, and auramine. A 2- $\mu$ m Historesin section. 4. Immature stigma pollinated at anthesis. Note dehydrated pollen grains. Squash preparation, stained with aniline blue. 5. Receptive stigma pollinated $2 \mathrm{~d}$ after anthesis. Pollen grains have germinated, and the pollen tubes grow towards the stigmatoid tissue between papillae. Squash preparation stained with aniline blue. 6. Degenerated stigma pollinated $4 \mathrm{~d}$ after anthesis. Pollen grain has germinated, but the pollen tube growth was arrested, shown by a swollen end. Squash preparation, stained with aniline blue. In Figs. 2-6, bar $=20 \mu \mathrm{m}$. 

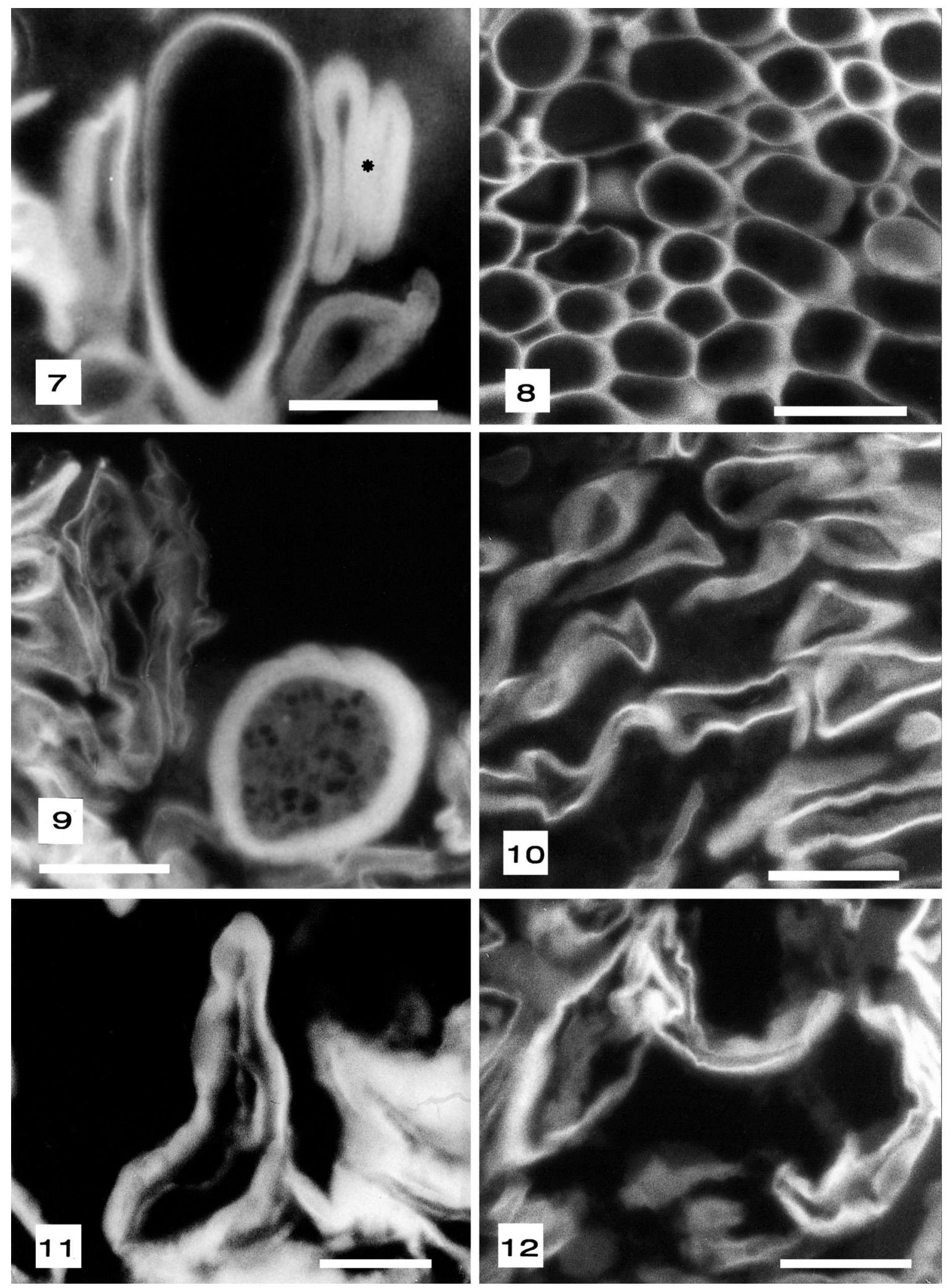

Figs. 7-12. Stigma maturation and degeneration in Pyrus communis. 7. Immature stigma pollinated at anthesis. Papilla is turgid and pollen grains (*) have not yet hydrated. 8. Stigmatoid tissue of an immature stigma. Intercellular space is free of intercellular matrix. 9. Receptive stigma, pollinated $2 \mathrm{~d}$ after anthesis. Papillae have collapsed, and pollen grains have germinated. Note secretion between papilla and pollen grain. 10. Stigmatoid tissue in a mature stigma. Cells have lost turgidity, and a intercellular matrix is present. 11. Degenerated stigma, $7 \mathrm{~d}$ old. Papillae have collapsed. 12. Degenerated stigmatoid tissue. Cells have collapsed, and the intercellular matrix has lost continuity. All figures are from $2-\mu \mathrm{m}$ historesin sections stained with calcofluor white, acridine orange, and auramine. Bar $=20 \mu \mathrm{m}$. 
$\mathbf{A}$
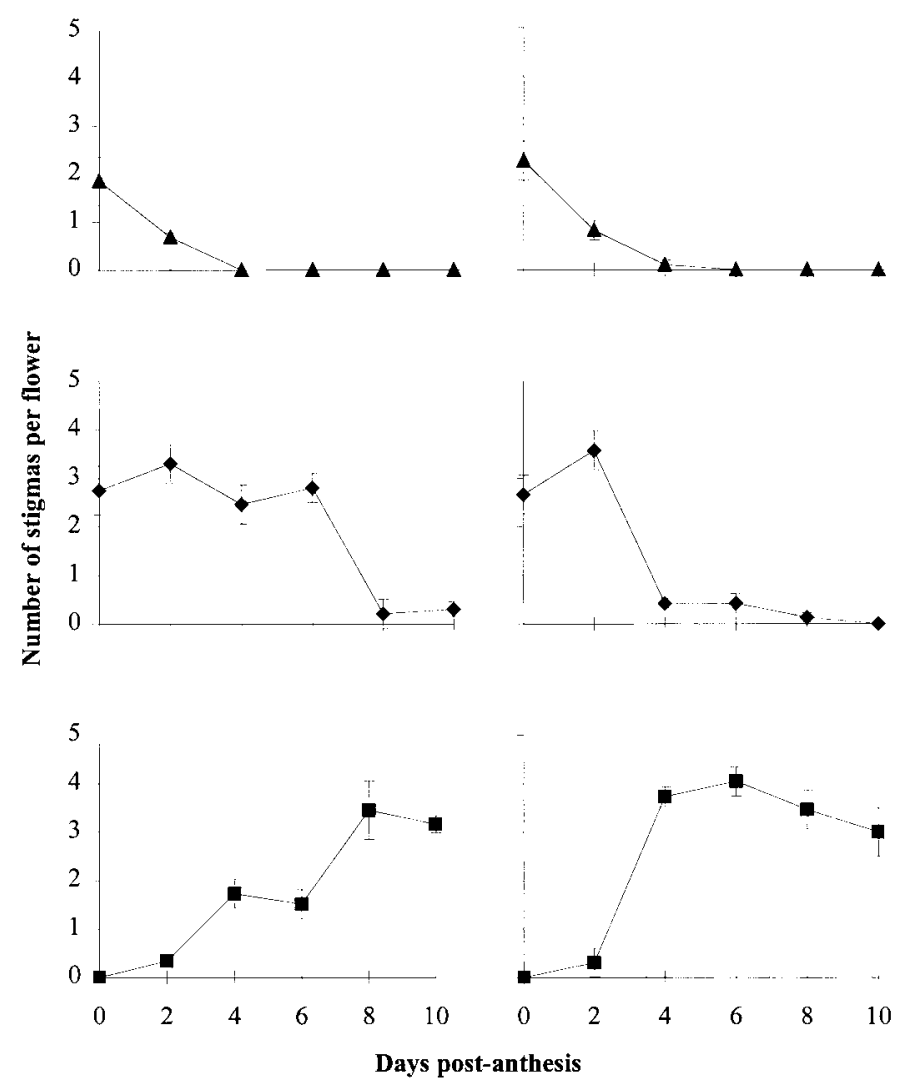

Fig. 13. Dynamics of stigmatic receptivity in Pyrus communis. Mean number of inmature $(\mathbf{\Delta})$, mature $(\boldsymbol{\nabla})$, and degenerated $(\square)$ stigmas per flower, in flowers pollinated at anthesis and 2, 4, 6, 8, and $10 \mathrm{~d}$ after anthesis for the two years of experiment. (A) Data from first year of experiment. (B) Data from second year of experiment.

tissue the cells are degenerating and the intercellular matrix shows a discontinuous appearance (Fig. 12).

Flower stigmatic asynchrony-To monitor the time for stigmatic maturation and degeneration, records were taken, under the microscope, of the different stigma types in a total of 90 flowers each year, 15 from each pollination day at $0,2,4$, 6,8 , and $10 \mathrm{~d}$ after anthesis. It was apparent that not all the stigmas in a flower were at the same developmental stage. Thus, immature and mature, and mature and degenerated, stigmas coexist within a flower, although the proportion of each one within a flower changes with time. Figure 13 shows the mean number of stigmas per flower in each developmental stage for two consecutive years. In both years the duration of stigmatic receptivity was different, lasting up to $6 \mathrm{~d}$ for the first year of experiment and only for $2 \mathrm{~d}$ for the second. However, the coexistence of stigmas at the three developmental stages within a flower was consistent over the two years. At anthesis not all the stigmas in a flower were receptive and mature stigmas coexisted with immature stigmas. In both years, the mean number of immature and mature stigmas per flower at anthesis was around 2 and 2.5, respectively (Fig. 13). Two days later, the number of receptive stigmas was slightly higher than at anthesis, probably because of a faster development from immature to mature stigmas than from mature to degenerate. At this time the first degenerate stigmas could be seen and the three developmental stages coexisted. A significant decrease of the proportion of mature stigmas did not occur until $8 \mathrm{~d}$ after anthesis in the first year, while it happened $4 \mathrm{~d}$ earlier in the second year.

\section{DISCUSSION}

Stigma development and stigmatic receptivity-In this work stigma development has been characterized in the pear flower from anthesis to degeneration. Stigma structure, exudate production, and pollen tube penetration are similar, as has been described for other genera of the Rosaceae family such as Malus and Prunus (Heslop-Harrison, 1976; Uwate and Lin, 1981; Heslop-Harrison and Heslop-Harrison, 1982; Viti, Bartolini, and Minnocci, 2000). A layer of mainly papillate cells composes the receptive surface. Below this, the stigmatoid tissue composed of several layers of cells connects this surface with the stylar transmitting tissue. Material for the surface secretion comes from papillae as well as from the cells of the stigmatoid tissue. Both exudate release and pollen tube penetration occur in the space between papillae. Apparently, and as was previously proposed, papillae secretion in the Rosaceae is released from the basal part of the cell (Heslop-Harrison and Heslop-Harrison, 1982), unlike in other families, such as Solanaceae, where secretion accumulates beneath the cuticle and is released following cuticle rupture (Konar and Linskens, 1966a, b; MacKenzie, Yoo, and Seabrook, 1990).

The study of pollen behavior following delayed pollination has shown three different stigmatic stages-immature, mature, and degenerated. Stigma receptivity is acquired in two subsequent steps that appear to be independently regulated. The transition of stigmas from an immature to a mature stage implies the acquisition of competence to support pollen hydration and germination, which is separate from the pollen adhesion ability characteristic of immature stigmas. Thus, immature stigmas were characterized by the inability of pollen grains to hydrate, $24 \mathrm{~h}$ after pollination. Interestingly, at this developmental stage part of the secretion already has been produced, coming from the stigmatoid cells just below the receptive surface, in a way similar to that described in Malus (HeslopHarrison, 1976). This secretion flows up through the space between papillae and alights on the stigmatic surface through breaking points in the cuticle (Heslop-Harrison and HeslopHarrison, 1982). Our observations suggest that stigmatic exudate in immature stigmas is required for pollen grain adhesion, although it is unlikely to be sufficient for the stigma to be receptive, to allow pollen hydration and germination. Pollen hydration occurs concomitantly with the loss of papillar turgidity. This is probably due to the fact that papillae release some of their intracellular content, and it is tempting to speculate that this secretion is required for pollen hydration. In apple, two phases in stigma exudate production have been distinguished (Heslop-Harrison, 1976). Upon flower opening the receptive surface of the stigma is already covered by secretion between the papillae. Interestingly, the main flow of secretion does not take place until a few hours later. However, it has not been shown whether this second release of material occurs together with papillar collapse.

Our results show that the onset of stigma degeneration in pear is marked by the inability of the stigma to support pollen tube growth, while pollen adhesion, hydration, and germination are maintained. Thus, pollen tube growth is abruptly arrested when the pollen tubes are no longer than the stigmatoid 
tissue length. This arrest occurs as the pollen tubes develop abnormally swelled tips. The mechanisms by which the stigma loses receptivity are poorly understood. In kiwi, cessation of stigma receptivity occurs concomitantly with papilla rupture and is manifested by the failure of pollen germination (Gonzalez, Coque, and Herrero, 1995a). However, in our study unreceptive stigmas of pear first impaired initial pollen tube growth, while pollen germination remained unaltered. This early arrest of growth precludes pollen tubes from penetrating the transmitting tissue and occurs concomitantly with the lack of a continuous intercellular matrix in the stigmatoid tissue, suggesting that a continuous intercellular matrix would be required for the pollen tube to proceed in its way towards the style.

According to our observations, the onset of both stigma receptivity and stigma degeneration are more likely to occur as a consequence of changes in the secretion, rather than because of physical changes suffered by the receptive surface. In fact, in wet stigmas the importance of the receptive tissue itself for stigmatic receptivity, although important for the production of secretion, is far from clear. Thus, Goldman, Goldberg, and Mariani (1994), using a transgenic tobacco plant in which the stigmatic secretory cells were ablated, demonstrated that this tissue is critical to produce exudate and then promote pollen germination and pollen tube growth. However, those processes could occur in the absence of the stigmatic secretory zone if secretion was artificially supplied. Later, it was established how lipids in the secretion were key components for pollen tube penetration in the stigmatoid tissue (Wolters-Arts, Lush, and Mariani, 1998). These lipids appear to play a primary role, providing an adequate influx of water for pollen grain hydration, germination, and orientation (Lush, Grieser, and Wolters-Arts, 1998). Probably lipidic composition of the secretion is also important for determining the timing of stigmatic receptivity acquisition and loss.

Stigmatic asynchronous development within a flower-Information derived from the analysis of the stigmatic types in flowers of different ages, following the classification of immature, mature, and degenerated stigmas described before, showed how stigmas within a flower are not at the same stage of development. Immature and mature, and mature and degenerated stigmas coexist within a single flower. Moreover, the three stigmatic types coexist in the whole population of flowers of the same age. While variation between years in the duration of stigmatic receptivity occurred, the pattern of stigma development was consistent over the two years of the experiment. Thus, stigmas in the pear flower developed asynchronously and within the flower a succession of stages in stigmatic receptivity occurs.

The fact that part of the stigmas in the pear gynoecium presents a delay in the time of receptivity in relation to anthesis was previously reported to be even of $4 \mathrm{~d}$ (Herrero, 1983). A difference between the time of female receptivity and flower opening in other species has been interpreted as a strategy to modulate pollen competition. This is thought to operate by synchronizing the time of pollen germination independently of the first pollen deposition. Thus, the size and genetic variability of the population of pollen grains arriving to the stigma are increased as much as stigma receptivity is delayed (Murdy and Carter, 1987; Hormaza and Herrero, 1994). The fact that pear stigmas are able to support pollen adhesion for a time prior to pollen germination suggests that such a system could be operating in pear.

Results herein not only show a delay of female receptivity in relation to anthesis, but also an asynchronous maturation of the stigmas within the pear flower. This behavior is probably a general characteristic of this species; in an early study on the reproductive biology of other pear cultivars, Modlibowska (1945) reported that upon flower opening receptivity was not reached by all the stigmas simultaneously. On the other hand, Jaumien (1968) also noted that ovules within a single ovary were not at the same stage of development. So, this asynchronous development might well be a general characteristic of the entire pear flower.

It is not known, however, whether this developmental performance might be common among other polycarpellar species, nor what its adaptive significance could be. Reproductive asynchrony has been predicted to be an efficient strategy for maximizing visitation rates of pollinators (Rathcke and Lacey, 1985; Ims, 1990). In this way, it is common for animal-pollinated plants to display asynchronous flowering among individuals within a population as well as among the flowers of one individual (Rathcke and Lacey, 1985). This strategy could also apply to the asynchronous carpel development within the pear flower described in this study.

Pear is the first species for which stigmatic asynchrony in a multicarpellar flower has been described, but it is not known how general this phenomenon of asynchronous stigma development might be among other species. This phenomenon can help explain the adaptive significance of polycarpy, particularly in populations where pollinator efficiency is low and/or unreliable pollination conditions exist.

\section{LITERATURE CITED}

CARr, S. G. M., AND D. J. CARR. 1961. The functional significance of syncarpy. Phytomorphology 11: 249-256.

Cowan, A. A., A. H. Marshall, and T. P. T. Michaelson-Yeates. 2000. Effect of pollen competition and stigmatic receptivity on seed set in white clover (Trifolium repens L.). Sexual Plant Reproduction 13: 37-42.

Decraene, L. P. R., AND E. Smets. 1998. Meristic changes in gynoecium morphology, examplified by floral ontogeny and anatomy. In S. J. Owens and P. J. Rudall [eds.], Reproductive biology, 85-112. Royal Botanic Garden, Kew, UK.

Delph, L. F., AND K. Havens. 1998. Pollen competition in flowering plants. In T. R. Birkhead and A. P. Moller [eds.], Sperm competition and sexual selection, 147-174. Academic Press, London, UK.

EgEA, J., AND L. Burgos. 1992. Effective pollination period as related to stigma receptivity in apricot. Scientia Horticulturae 52: 77-83.

ENDRESS, P. K. 1982. Syncarpy and alternative modes of escaping disadvantages of apocarpy in primitive angiosperms. Taxon 31: 48-52.

FEDER, N., AND T. P. O'BRIEN. 1968. Plant microtechnique: some principles and new methods. American Journal of Botany 55: 123-142.

Fiebig, A., J. A. Mayfield, N. L. Miley, S. Chau, R. L. Fischer, And D. PREUSS. 2000. Alterations in CER6, a gene identical to CUT1, differentially affect long-chain lipid content on the surface of pollen and stems. Plant Cell 12: 2001-2008.

FREE, J. B. 1964. Comparison of the importance of insect and wind pollination of apple trees. Nature 201: 726-727.

Galen, C. J., A. Shykoff, And R. C. Plowright. 1986. Consequences of stigma receptivity schedules for sexual selection in flowering plants. American Naturalist 127: 463-476.

GHosh, S., AND K. R. ShIVANNA. 1982. Anatomical and cytochemical studies on the stigma and style in some legumes. Botanical Gazette 143: 311 318.

Goldman, M. H. S., R. B. Goldberg, and C. Mariani. 1994. Female sterile tobacco plants are produced by stigma-specific cell ablation. EMBO Journal 13: 2976-2984.

González, M. V., M. Coque, and M. Herrero. 1995a. Papillar integrity 
as an indicator of stigmatic receptivity in kiwifruit (Actinidia deliciosa). Journal of Experimental Botany 46: 263-269.

GonzÁlez, M. V., M. CoQue, AND M. Herrero. 1995b. Stigmatic receptivity limits the effective pollination period in kiwifruit. Journal of the American Society of Horticultural Sciences 120: 199-202.

Guerrero-Prieto, V. M., M. D. VAsilakakis, AND P. B. Lombard. 1985. Factors controlling fruit set of 'Napoleon' sweet cherry in western Oregon. HortScience 20: 913-914.

Herrero, M. 1983. Factors affecting fruit set in 'Agua de Aranjuez' pear. Acta Horticulturae 139: 91-96.

Heslop-Harrison, J. 1976. A new look at pollination. East Malling Research Station Report for 1976: 141-157.

Heslop-Harrison, J., AND Y. Heslop-Harrison. 1982. The plant cuticle. In D. F. Cutler, K. L. Alvin, and C. E. Price [eds.], Linnean Society Symposium Series 10, 99-119. Academic Press, London, UK.

Heslop-Harrison, Y. 1977. The pollen stigma interaction: pollen tube penetration in Crocus. Annals of Botany 41: 913-922.

Heslop-Harrison, Y. 2000. Control gates and micro-ecology: the pollenstigma interaction in perspective. Annals of Botany 85(Supplement A): $5-13$.

Heslop-Harrison, Y., AND K. R. Shivanna. 1977. The receptive surface of the angiosperm stigma. Annals of Botany 41: 1233-1258.

Hormaza, J. I., AND M. Herrero. 1994. Gametophytic competition and selection. In E. G. Williams, R. B. Knox, and A. E. Clarke [eds.], Genetic control of self-incompatibility and reproductive development in flowering plants, 372-400. Kluwer Academic, Dordrecht, Netherlands.

Hughes, J., AND M. E. MCCully. 1975. The use of an optical brightener in the study of plant structure. Stain Technology 50: 319.

Hülskamp, M., S. D. Kopczak, T. F. Horejsi, B. K. Kinl, and R. E. PruitT. 1995. Identification of genes required for pollen-stigma recognition in Plant Journal 8: 703-714.

IMS, R. A. 1990. The ecology and evolution of reproductive synchrony. Trends in Ecology and Evolution 5: 135-140.

JAUMIEN, F. 1968. The cause of poor bearing trees of the variety 'Doyenne du Comice'. Acta Agrobotanica 21: 75-106.

JeFFERIES, C. J., AND A. R. BelcheR. 1974. A fluorescent brightener used for pollen tube identification in vivo. Stain Technology 49: 199-202.

JoHANSEN, D. A. 1940. Plant microtechnique. McGraw-Hill, New York, New York, USA.

JuncosA, A. M., AND B. D. Webster. 1989. Pollination in Lupinus nanus subsp. latifolius (Leguminosae). American Journal of Botany 76: 59-66.

Kalisz, S., D. Vogler, B. Fails, M. Finer, E. Shepard, T. Herman, and R. GonZales. 1999. The mechanism of delayed selfing in Collinsia verna (Scrophulariaceae). American Journal of Botany 86: 1239-1247.

KonAR, R. N., AND H. F. Linskens. 1966a. The morphology and anatomy of the stigma of Petunia hybrida. Planta 71: 356-371.

KonAR, R. N., AND H. F. Linskens. 1966b. Physiology and biochemistry of the stigmatic fluid of Petunia hybrida. Planta 71: 378-387.

KRESS, W. J. 1981. Sibling competition and evolution of pollen unit, ovule number and pollen vector in angiosperms. Systematic Botany 6: 101112.

LABARCA, C., M. KROH, AND F. LoEwUs. 1970. The composition of stigmatic exudate from Lilium longiflorum. Plant Physiology 46: 150-156.

LinsKens, H. F., AND K. EsSER. 1957. Uber eine spezifische Anfärbung der
Pollen-shläuche und die Zagl Kallosapropten nach selbstung und fremdung. Naturwiss 44: 16.

Lush, W. M., F. Grieser, AND M. Wolters-Arts. 1998. Directional guidance of Nicotiana alata pollen tubes in vitro and on the stigma. Plant Physiology 118: 733-741.

Mackenzie, C. J., B. Y. Yoo, and J. E. A. SeabrooK. 1990. Stigma of Solanum tuberosum cv. Shepody: morphology, ultrastructure, and secretion. American Journal of Botany 77: 1111-1124.

Mansvelt, E. L., And A. H. M. J. Hattingh. 1987. Scanning electron microscopy of pear blossom invasion by Pseudomonas syringae pv. syringae. Canadian Journal of Botany 65: 2523-2529.

Martin, F. W. 1969. Compounds from the stigmas of ten species. American Journal of Botany 56: 1023-1027.

ModlibowsKA, I. 1945. Pollen tube growth and embryo-sac development in apples and pears. Journal of Pomology 21: 57-89.

Murdy, W. H., AND M. E. B. CARTER. 1987. Regulation of the timing of pollen germination by the pistil in Talinum mengesii (Portulacaceae). American Journal of Botany 74: 1888-1892.

Nicholas, J. R., P. J. GATES, AND P. GRIERSON. 1986. The use of fluorenscence microscopy to monitor root development in micropropagated explants. Journal of Horticultural Science 61: 417-421.

Owens, S. J., AND F. M. Kimmins. 1981. Stigma morphology in Commelinaceae. Annals of Botany 47: 771-783.

Preuss, D., B. Lemieux, G. Yen, AND R. W. Davis. 1993. A conditional sterile mutation eliminates surface components from Arabidopsis pollen and disrupts cell signaling during fertilization. Genes and Development 7: 974-985

RATHCKE, B., AND E. P. LACEY. 1985. Phenological patterns of terrestrial plants. Annual Review of Ecology and Systematics 16: 179-214.

Sabatini, D. D., K. BenCh, And R. J. Barrnett. 1963. Cytochemistry and electron microscopy. The preservation of cellular ultrastructure and enzimatic activity by aldehyde fixation. Journal of Cell Biology 17: 1958 .

SANZOL, J., AND M. Herrero. 2001. The effective pollination period in fruit trees. Scientia Horticulturae 90: 1-17.

SANZOL, J., AND M. Herrero. 2002. Identification of self-incompatibility alleles in pear (Pyrus communis L.) cultivars. Euphytica (in press).

Uma-ShaAnker, R., N. K. Ganeshaiah, and K. S. Bawa. 1988. Parent offspring conflict, sibling rivalry and brood size patterns in plants. Annual Review of Ecology and Systematics 19: 177-205.

Uwate, W. J., AND J. Lin. 1981. Development of the stigmatic surface of Prunus avium L., sweet cherry. American Journal of Botany 68: 11651176.

Viti, R., S. BARTOlini, AND A. MinnOCCI. 2000. Morphological structure of stigma and style of several genotypes of Prunus armeniaca L. Plant Biosystems 134: 45-51.

Willingale, J., P. G. Mantle, and R. P. Thakur. 1986. Post-pollination stigmatic constriction, the basis for ergot resistance in selected lines of pearl millet. Phytopathology 76: 536-539.

Wolters-Arts, M., W. M. Lush, And C. Mariani. 1998. Lipids are required for directional pollen-tube growth. Nature 392: 818-820.

WyatT, R. 1983. Pollinator-plant interactions and the evolution of breeding systems. In L. Real [ed.], Pollination biology, 51-95. Academic Press, Orlando, Florida, USA. 